\title{
SEISMIC TRAVELTIME TOMOGRAPHY APPLIED TO DATA FROM MIRANGA FIELD, RECÔNCAVO BASIN, BRAZIL
}

\author{
Vitor Hugo Serravalle Reis Rodrigues ${ }^{1}$ and Amin Bassrei
}

\begin{abstract}
The growing global demand for hydrocarbons has tested the limits of oil exploration and exploitation technologies. Among the seismic methods, tomography is an alternative means for high-resolution characterization of reservoirs, and it enables a more efficient recovery of both new and mature fields. In this work we apply the traveltime inversion to crosswell data from Miranga Field, in the Recôncavo Basin, State of Bahia. The objective is to estimate the two-dimensional velocity distribution in the region between the wells. We use linearized inversion through the Levenberg-Marquardt scheme. The linear system during the iteration is solved by the Conjugate Gradient method. Because the inverse problem is ill-posed we apply regularization by derivative matrices of first and second orders, and the optimal regularization parameter is chosen using the $L$-curve and the $\Theta$-curve.
\end{abstract}

Keywords: reservoir characterization, traveltime tomography, seismic inversion, regularization, Recôncavo Basin.

RESUMO. A crescente demanda mundial por hidrocarbonetos tem testado os limites das tecnologias de exploração e explotação de petróleo. Dentro dos métodos sísmicos, a tomografia surge como alternativa de caracterização de alta resolução dos reservatórios, viabilizando uma recuperação mais eficiente de campos novos e maduros. Este trabalho é o resultado de um estudo da inversão de dados de tempos de trânsito entre dois poços do Campo de Miranga, na Bacia do Recôncavo. 0 objetivo é estimar a distribuição de velocidades na região entre os dois poços. Para tanto, será usada a inversão linearizada, também conhecida como inversão de Levenberg-Marquardt, combinada com o método Gradiente Conjugado. Ambos os métodos foram testados com regularização por matrizes de derivadas de primeira e segunda ordens. 0 parâmetro de regularização ótimo foi escolhido por meio da curva $L$ e da curva $\Theta$.

Palavras-chave: caracterização de reservatórios, tomografia de tempos de trânsito, inversão sísmica, regularização, Bacia do Recôncavo.

\footnotetext{
${ }_{1}^{1}$ Serviço Geológico do Brasil (CPRM) / Universidade Federal da Bahia (UFBA), Institute of Geosciences, Rua Barão de Jeremoabo, s/n, Ondina, 40170-115 Salvador, BA, Brazil. Phone: +55(71) 3283-8508 - E-mail: vitorhugoserravalle@gmail.com

2 Universidade Federal da Bahia, Research Center in Geophysics and Geology (UFBA/CPGG) and INCT-GP - National Institute of Science and Technology of Petroleum Geophysics, Institute of Geosciences, Rua Barão de Jeremoabo, s/n, Ondina, 40170-115 Salvador, BA, Brazil. Phone: +55(71) 3283-8508 - E-mail: bassrei@ufba.br
} 


\section{INTRODUCTION}

After nearly a century since of the beginning of petroleum industry in Brazil, many early prolific basins are now in the declining stage of hydrocarbon production. The Recôncavo Basin, which is the oldest Brazilian basin in activity, faces the challenge of maintaining economic levels of oil production decades after reaching its peak in the 1970s. At its current level of maturity, the Recôncavo Basin Fields require sophisticated techniques of secondary and tertiary oil hydrocarbon recovery. Such techniques demand a more detailed understanding of the geological substratum that goes beyond those offered by traditional exploration seismology.

As part of the geophysical imaging tools, seismic tomography utilizes higher frequency sources than are used by standard seismic methods to obtain a characterization result with better resolution. In an ideal situation, sources and receivers should be placed all around the object to be imaged. In geophysics, however, two acquisition geometries are mainly used: Vertical Seismic Profile (VSP), where the sources are arranged on the surface and receivers along the well, and Cross Well Profile (XWP), with sources and receivers distributed along different wells. XWP is the geometry used in this work.

The tomographic technique can be divided into two classes: traveltime tomography, which considers only the P wave traveltime between each source-receiver pair, and dynamic tomography, which uses the shape of the wave that arrives at the receiver.

Having the traveltimes for various source-receiver pairs, one must choose the most suitable inversion procedure, to obtain a model that represents the subsurface velocity distribution. Inversion is one of the most studied topics in geophysics, with many schemes and algorithms presented in the literature. For this work the Levenberg-Marquardt inversion was chosen. In this method, each iteration requires the solution of a linear system, so the Conjugate Gradient method optimized for operations with sparse matrix was selected as the algorithm for solving the linearized inverse problem.

To minimize the problems with stability and ambiguity of the solution, we used regularization by derivative matrices. Regularization transforms the original problem into another one with a more stable solution. This process requires special care to choose the regularization parameter, which defines the balance between the smallest error in the data and the amount of regularization in the inversion. As a result, strategies based on L-curve and $\Theta$ curve are evaluated as criteria for choosing the optimal regularization factor.

\section{INVERSE PROBLEMS, CONJUGATE GRADIENT AND LEVENBERG-MARQUARDT}

One of goals in geophysics is to reconstitute the subsurface physical parameters by using data from surface, well or aerial surveys.
However, the equations that dictate the physical laws allow us to only know the response data from a defined model, in a process known as forward modeling (Snieder \& Trampert, 1999). The inverse problem arises as a tool, with its limitations, to work around this issue; that is, it attempts to estimate a model that fits the measured data.

In general, geophysical data are obtained in discrete form, which allows for a matrix formulation of the inverse problem. Let $\boldsymbol{d}=\left[d_{1} d_{2}, \ldots, d_{M}\right]^{T}$ be the data parameters vector and $\boldsymbol{m}=\left[m_{1} m_{2}, \ldots, m_{N}\right]^{T}$ be the model parameters vector; in this case, for a linear geophysical problem, $\boldsymbol{d}=\boldsymbol{G} \boldsymbol{m}$. If the matrix $\boldsymbol{G}_{M \times N}$ is known and invertible, then the system solution is easily obtained as $\boldsymbol{m}=\boldsymbol{G}^{-1} \boldsymbol{d}$. However, geophysical problems tend to be more complex. Most of the problems are nonlinear, and even when they are linear, $\boldsymbol{G}$ is not easily invertible and requires special treatment for various reasons.

Inverse problems in geophysics are usually ill-posed, mainly because of the instability and non-uniqueness of its solutions. In addition to the use of a priori information, such as geological or other geophysical data, it is common to use a numerical treatment that stabilizes the solution, such as regularization.

Because it is a fast and effective method, the Conjugate Gradient method is one of the most used methods for solving linear systems in the presence of symmetric and positive definite matrices. Consider the linear system $\boldsymbol{G} \boldsymbol{m}=\boldsymbol{d}$. Conjugate Gradient is an iterative method that converges to a solution in fewer than $N$ iterations, where $N$ is the order of the matrix $G$ of the system. Because of rounding errors during computational operations, the estimation after the number of iterations $\boldsymbol{m}_{N}$ will be not an exact solution but a good approximation of it (Hestenes \& Stiefel, 1952).

The solution of the system will converge to the minimum of the quadratic form associated with a minimum of the objective function

$$
S(\boldsymbol{m})=\frac{1}{2} \boldsymbol{m}^{T} \boldsymbol{G} \boldsymbol{m}-\boldsymbol{m}^{T} \boldsymbol{d}+c .
$$

Given an initial solution $\boldsymbol{m}_{0}$, the Conjugate Gradient steps for this system are shown below:

$$
\begin{aligned}
& \boldsymbol{r}_{0}=\boldsymbol{d}-\boldsymbol{G m}_{0} \\
& \boldsymbol{p}_{0}=\boldsymbol{r}_{0} \\
& \mathrm{D} 0 i=0, N \\
& \alpha_{i}=\frac{\boldsymbol{r}_{i}^{T} \boldsymbol{r}_{i}}{\boldsymbol{p}_{i}^{T} \boldsymbol{G} \boldsymbol{p}_{i}}, \\
& \boldsymbol{m}_{i+1}=\boldsymbol{m}_{i}+\alpha_{i} \boldsymbol{p}_{i},
\end{aligned}
$$




$$
\begin{aligned}
& \boldsymbol{r}_{i+1}=\boldsymbol{r}_{i}-\alpha_{i} \boldsymbol{G} \boldsymbol{p}_{i}, \\
& \beta_{i}=-\frac{\boldsymbol{r}_{i+1}^{T} \boldsymbol{G} \boldsymbol{p}_{i}}{\boldsymbol{p}_{i}^{T} \boldsymbol{G} \boldsymbol{p}_{i}}, \\
& \boldsymbol{p}_{i+1}=\boldsymbol{r}_{i+1}+\beta_{i} \boldsymbol{p}_{i} \\
& \text { Enddo }
\end{aligned}
$$

In the above scheme $\boldsymbol{p}_{i}$ and $\boldsymbol{r}_{i}$ are auxiliary vectors and $\alpha_{i}$ and $\beta_{i}$ are auxiliary scalars used for the solution update. To better manage the computing resources in the specific case of sparse matrices found in tomography, the storage scheme proposed in the YALE sparse matrix package is used in this paper (Eisenstat et al., 1982). This format allows us to reduce operations with zero elements, which are massively present in a sparse matrix, thereby significantly improving the computational efficiency of the algorithm.

Let $\boldsymbol{d}$ be the data vector, and $\boldsymbol{m}$ be the model parameters; in this case, the forward modeling is given by

$$
\boldsymbol{d}=g(\boldsymbol{m}),
$$

where $g$ is the forward modeling operator (Sen \& Stoffa, 2013). In most geophysical problems, $g$ is a nonlinear operator. Therefore, the objective function that minimizes the square error is no longer a paraboloid with a single minimum point. Instead, the objective function of nonlinear problems is formed by a rough "sheet" with many local minima. Thus, one can classify the nonlinear inversion methods into two main groups: global scope and local scope.

Classified as a local scope method, the linearized inversion or Levenberg-Marquardt inversion relies on the basic assump- tion that data vary linearly with the model parameters in the region close to the model $\boldsymbol{m}^{k}$. Expanding the error vector in a Taylor series and considering only its linear components, we obtain

$$
\Delta \boldsymbol{d}^{k}=\boldsymbol{G}^{k} \Delta \boldsymbol{m}^{k}
$$

where $k$ indicates the iteration number, $\boldsymbol{G}^{k}$ is known as the sensibility matrix (which is composed of forward modeling operator derivatives), $\Delta \boldsymbol{d}^{k}$ represents the data error and $\Delta \boldsymbol{m}^{k}$ is the model update, where

$$
\boldsymbol{m}^{k+1}=\boldsymbol{m}^{k}+\Delta \boldsymbol{m}^{k} .
$$

Thus, it is possible to reduce the nonlinear problem to an iterative process that consists of successive linear problems given by Eq. (3). The linear system can still be numerically restructured to meet the demands of regularization.

\section{REGULARIZATION, L-CURVE AND @-CURVE}

In the numerical solution of discrete ill-posed problems, regularization techniques are used to make inversion a more stable problem. These techniques solve a similar problem that is more robust with respect to variations in the input data (Oliveira, 2013). In this work, the regularization by derivative matrices proposed by Twomey (1963) was used.

The solution for regularization by derivative matrices is obtained minimizing the objective function $S(\boldsymbol{m})$, defined as (Bassrei \& Rodi, 1993)

$$
S(\boldsymbol{m})=\boldsymbol{e}^{T} \boldsymbol{e}+\lambda L_{n} .
$$

In Eq. (5), $\lambda$ is a positive constant known as the regularization parameter and dictates the regularization intensity added to the original problem. The term $L_{n}$ represents the following matrix operations:

$$
L_{n}=\left\|\boldsymbol{l}_{n}\right\|^{2}=\left(\boldsymbol{D}_{n} \boldsymbol{m}\right)^{T} \boldsymbol{D}_{n} \boldsymbol{m},
$$

where $\boldsymbol{D}_{n}$ indicates the derivative matrix used, and $n$ denotes the regularization order. In the case that $n=0, \boldsymbol{D}_{0}$ is equal to the identity matrix and the problem reduces to a damped solution. When $n=1$, the product $\boldsymbol{l}_{1}=\boldsymbol{D}_{1} \boldsymbol{m}$ represents the first differential and is known as flatness, with

$$
\boldsymbol{D}_{1}=\left(\begin{array}{ccccccc}
1 & -1 & 0 & \ldots & 0 & 0 & 0 \\
0 & 1 & -1 & & 0 & 0 & 0 \\
& \vdots & & \ddots & & \vdots & \\
0 & 0 & 0 & & 1 & -1 & 0 \\
0 & 0 & 0 & \cdots & 0 & 1 & -1
\end{array}\right)
$$


For the second-order regularization ( $n=2$ ), or roughness, the product $\boldsymbol{l}_{2}=\boldsymbol{D}_{2} \boldsymbol{m}$ represents the second differential:

$$
\boldsymbol{D}_{2}=\left(\begin{array}{ccccccccccc}
1 & -2 & 1 & 0 & \ldots & 0 & 0 & 0 & 0 \\
0 & 1 & & -2 & 1 & & 0 & 0 & 0 & 0 & \\
& & \vdots & & & \ddots & & & \vdots & & \\
0 & 0 & 0 & 0 & & & 1 & -2 & 1 & 0 \\
0 & 0 & 0 & 0 & & & 0 & 1 & -2 & 1
\end{array}\right) .
$$

Replacing $L_{n}=\left(\boldsymbol{D}_{n} \boldsymbol{m}\right)^{T} \boldsymbol{D}_{n} \boldsymbol{m}$ in Eq. (5) leads to

$$
S(\boldsymbol{m})=(\boldsymbol{d}-\boldsymbol{G} \boldsymbol{m})^{T}(\boldsymbol{d}-\boldsymbol{G} \boldsymbol{m})+\lambda\left(\boldsymbol{D}_{n} \boldsymbol{m}\right)^{T} \boldsymbol{D}_{n} \boldsymbol{m} .
$$

When $\lambda=0$, the inversion is reduced to the Least Squares Method. Minimizing $S(\boldsymbol{m})$ gives us

$$
\frac{\partial S(\boldsymbol{m})}{\partial \boldsymbol{m}}=2 \boldsymbol{G}^{T} \boldsymbol{G} \boldsymbol{m}-2 \boldsymbol{G}^{T} \boldsymbol{d}+2 \lambda \boldsymbol{D}_{n}^{T} \boldsymbol{D}_{n} \boldsymbol{m}=0 .
$$

With some algebra, Eq. (10) leads us to

$$
\left(\boldsymbol{G}^{T} \boldsymbol{G}+\lambda \boldsymbol{D}_{n}^{T} \boldsymbol{D}_{n}\right) \boldsymbol{m}^{e s t}=\boldsymbol{G}^{T} \boldsymbol{d},
$$

or

$$
\boldsymbol{m}^{e s t}=\left(\boldsymbol{G}^{T} \boldsymbol{G}+\lambda \boldsymbol{D}_{n}^{T} \boldsymbol{D}_{n}\right)^{-1} \boldsymbol{G}^{T} \boldsymbol{d}
$$

Applying the Levenberg-Marquardt inversion with regularization, the linear system of Eq. (3) becomes

$$
\left(\boldsymbol{G}^{T}\right)^{k} \Delta \boldsymbol{d}^{k}=\left(\boldsymbol{G}^{T} \boldsymbol{G}+\lambda \boldsymbol{D}_{n}^{T} \boldsymbol{D}_{n}\right)^{k} \Delta \boldsymbol{m}^{k} .
$$

Properly choosing the regularization parameter is crucial to the success of regularization. The purpose is to find a balance between smoothing and minimum error in a linear system solution; the smoother the solution is, the more distant it will be from the original problem. There are many criteria for choosing the best value of $\lambda$; here, the L-curve and an extension of it, the $\Theta$-curve, are discussed.

The optimum $\lambda$ chosen by the L-curve is a compromise between a good fit to the data and the model smoothness. Reintroduced in the literature by Hansen (1992), the L-curve is drawn as a parametric graph of $\lambda$; that is, each point of the curve is associated with a model estimated by $\lambda$. On the $x$-axis are the magnitudes of the error vector $\|\boldsymbol{e}\|_{2}$, and on the $y$-axis are the values of $\left\|\boldsymbol{D}_{n} \boldsymbol{m}\right\|_{2}$. Because the graph is shown in a log-log scale, the curve resembles the shape of the letter "L", as observed in Figure 1.

According to Hansen (1992), the L-curve "knee" (Fig. 1) is related to the value of $\lambda$ that represents the best match between the error of the solution and the smoothness imposed by regularization.

Finding the tipping point, or "knee", of the L-curve visually can sometimes be an ambiguous and laborious task, especially in the case of inversion with a high number of iterations. There are several known criteria for estimating the "knee" of the L-curve. Santos (2006) proposed a criterion based on a curve that represents the cosine of the angle between adjacent segments of the discrete representation of the L-curve (Fig. 2).

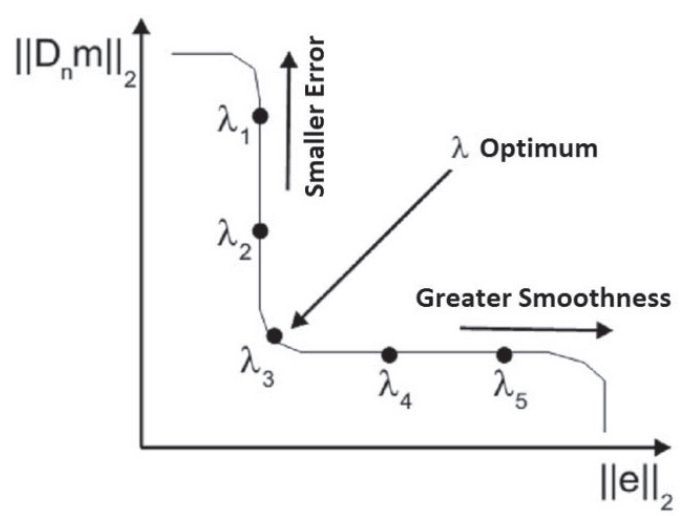

Figure 1 - Representation of the L-curve and its tipping point. Modified from Santos (2006).

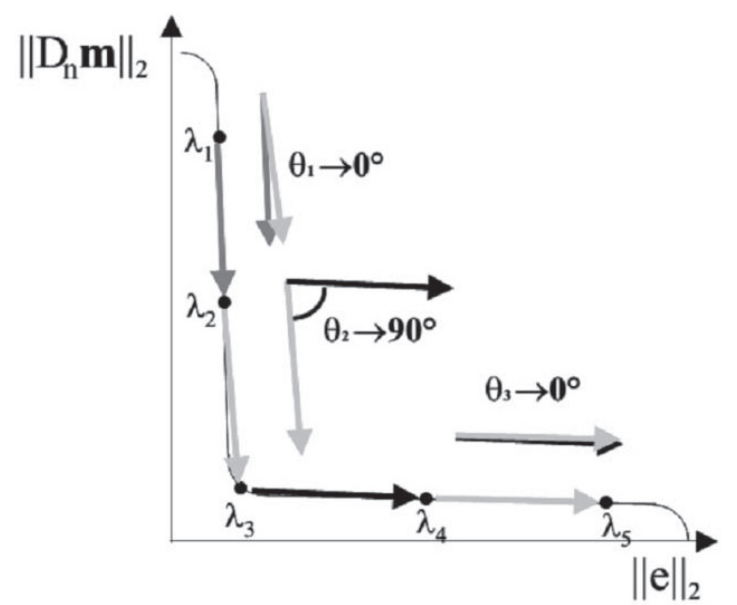

Figure 2 - Construction of the $\Theta$-curve from the L-curve. Modified from Santos (2006). 
This scheme takes advantage of the pronounced curvature at the tipping point in the L-curve; as a result, the $\Theta$-curve minimum is associated with the "knee" of the L-curve, or the optimum value for $\lambda$. However, other than the local minimum will appear. To ensure that this minimum point is in fact the "knee" of the L-curve, one can require the second derivative to be positive at this point.

\section{TRAVELTIME TOMOGRAPHY, RAY TRACING AND RAY LINKING}

Traveltime seismic tomography, unlike waveform tomography, measures only the propagation time of the $\mathrm{P}$ wave between the source and the receiver. More specifically, in this study, given special attention is given to the XWP (Cross Well Profile) geometry.

The traveltime of the $i$-th ray can be given by the following line integral:

$$
t_{i}=\int_{R_{i}} s(x, z) d l, \quad i=1, \ldots M,
$$

where $M$ is the number of source-receiver pairs, $R_{i}$ is the path of $i$-th ray and $s(x, z)=1 / v(x, z)$ is the slowness at the point $(x, z)$. It is possible to transform the medium in a grid with $N$ constant velocity rectangles. In that case, the above equation becomes

$$
t_{i}=\sum_{j=1}^{N} g_{i j} s_{j}, \quad i=1, \ldots, M
$$

where $g_{i j}$ represents $i$-th ray length inside the $j$-th rectangle. Equation (15) can be rewritten as

$$
t=G s .
$$

Fermat's Principle states that the traveltime is stationary with respect to first-order changes in the ray-path. That is, for small changes in slowness $\boldsymbol{s}$, the matrix $\boldsymbol{G}$ remains approximately the same. Let the first-order deviation in slowness be $\Delta s=$ $s^{k+1}-s^{k}$ and the tomographic matrix generated by $s^{k}$ be $\boldsymbol{G}^{k}$. According to Fermat's Principle, the traveltime deviation will be given by

$$
\Delta \boldsymbol{t}^{k}=\boldsymbol{t}^{k+1}-\boldsymbol{t}^{k}=\boldsymbol{G}^{k} \boldsymbol{\Delta} \boldsymbol{s}^{k},
$$

which brings us back to Eq. (3).

To properly choose a ray tracing algorithm, one must consider the singularities of the field in which the ray is intended to propagate. In this work, the algorithm of Andersen \& Kak (1982) is used, which was inspired by the algorithm of Johnson et al. (1975). Knowing that the Euler equation is a necessary condition for the existence of extreme values in variation integral, we can apply it to Fermat's principle and obtain the ray differential equation for a homogeneous medium:

$$
\frac{d}{d s}\left(n \frac{d \boldsymbol{r}}{d s}\right)=\nabla n,
$$

where $\boldsymbol{r}$ is the position vector of the points of the path. The above equation develops to

$$
\left(\nabla n \cdot \frac{d \boldsymbol{r}}{d s}\right) \frac{d \boldsymbol{r}}{d s}+n \frac{d^{2} \boldsymbol{r}}{d s^{2}}=\nabla n .
$$
Series:

The function $\boldsymbol{r}(s)$ can be expanded in second-order Taylor

$$
\boldsymbol{r}(s+\Delta s)=\boldsymbol{r}(s)+\frac{d \boldsymbol{r}}{d s} \Delta s+\frac{1}{2} \frac{d^{2} \boldsymbol{r}}{d s^{2}} \Delta s^{2} .
$$

Next, the term $\frac{d^{2} r}{d s^{2}}$ is isolated in Eq. (19) and substituted into Eq. (20):

$$
\begin{gathered}
\boldsymbol{r}(s+\Delta s)=\boldsymbol{r}(s)+\frac{d \boldsymbol{r}}{d s} \Delta s \\
+\frac{1}{2 n}\left[\nabla n-\left(\nabla n \cdot \frac{d \boldsymbol{r}}{d s}\right) \frac{d \boldsymbol{r}}{d s}\right] \Delta
\end{gathered}
$$

The consecutive points $P_{1}\left(x_{k}, z_{k}\right)$ and $P_{2}\left(x_{k+1}, z_{k+1}\right)$ of the ray path are connected by the equations:

$$
\begin{aligned}
x_{k+1}=x_{k} & +\cos \alpha_{k} \Delta s \\
& +\frac{1}{2 n_{k}}\left(n_{k, x}-d_{k} \cos \alpha_{k}\right) \Delta s^{2}, \\
y_{k+1}=y_{k} & +\sin \alpha_{k} \Delta s \\
& +\frac{1}{2 n_{k}}\left(n_{k, z}-d_{k} \sin \alpha_{k}\right) \Delta s^{2},
\end{aligned}
$$

where $n_{k}$ is the refraction index, $n_{k, x}$ and $n_{k, z}$ are the refraction index derivative at the directions $x$ and $z$, respectively, $\alpha_{k}$ is the angle between the tangent line to the path and the horizontal line and $d_{k}=s_{k, x} \cos \alpha_{k}+s_{k, z} \sin \alpha_{k}$.

Equations (22) and (23) build the ray path given a velocity model and a start angle $\alpha_{0}$. In most cases where ray tracing is applied, e.g., tomographic survey simulations, the problem to be solved is to find the traveltime for a given source-receiver pair. Ray linking is a technique that searches for a start angle in which the ray path links a given source to a given receiver.

The iterative Newton-Raphson method is used for the Ray linking. Starting with an angle $\theta_{2}$, which could be the angle formed by the straight line that links a source to a receiver, and a deviation $\Delta \theta$, two more angles are defined:

$$
\begin{aligned}
& \theta_{1}=\theta_{2}-\Delta \theta, \\
& \theta_{3}=\theta_{2}+\Delta \theta .
\end{aligned}
$$


The updated angle $\theta_{2}^{\prime}$ is given by

$$
\theta_{2}^{\prime}=\theta_{2} \pm \frac{2 d_{2 r}(\Delta \theta)}{d_{13}}
$$

where $d_{2 r}$ is the distance between the final coordinates of ray 2 with angle $\theta_{2}$ and the receiver and $d_{13}$ is the distance between the final coordinates of rays 1 and 3 with angles $\theta_{1}$ and $\theta_{3}$, respectively. The sign of the equation depends on the direction of angular growth and the relative positions of the final coordinates of ray 2 and the receiver.

\section{RECÔNCAVO BASIN}

The Recôncavo Basin plays a central role in the Brazilian oil industry history. Home to early production wells, its fields have already reached the peak of the production curve, which classify them as mature fields. Therefore, efficient hydrocarbon recovery is deeply dependent on good subsurface imaging, which can provide new strategies for well drillings and fluid injection for secondary recovery.

As the southernmost compartment of the Recôncavo-TucanoJatobá Rift system, the Recôncavo Basin is a series of elongated asymmetric grabens with direction NE-SO, which composes a intracontinental rift of direction N-S (Santos et al., 1990). Its origin is related to the Gondwana rifting during the Eocretaceous. This continental splitting created some aborted rifts in the Brazilian continental margin.

The sedimentary package of the Brazilian continental margin is typically subdivided into four supersequences: Paleozoic, Pre-Rift, Sin-Rift, Post-Rift, with only the last three actually belongs to the Recôncavo Basin. The Pre-Rift stage is associated with the crust flexure caused by the initial extensional efforts. This megasequence is characterized by fluvial and fluvial-deltaic siliciclastic rocks that were deposited under oxidative conditions. As the subsidence rate accelerates, the sediments of the Sin-Rift stage are deposited: lake sediments (siliciclastic and carbonate) and fluvial-deltaic packages.

The most important petroleum system is formed by the Candeias Formation lacustrine shales (source rock) and sandstones from the Sergi Formation (reservoir), both of which are from the Sin-Rift stage. Normal faults cause source and reservoir rocks to be positioned side by side. Shales from Candeias Formation play an important role as seal rocks.

Miranga, illustrated in Figure 3 (from Milani \& Araújo, 2003), was one of the first fields found with the support of seismic exploration in Brazil and has oil reserves of approximately 119 million barrels. The shale diapirism was a key factor in the structural configuration of this field. Shale domes from Candeias Formation surround the producer region and control the normal faults of the region. The reservoir is composed of sandstones of the Ilhas Group, Marfim and Pojuca Formations, structured as a faulted anticlinal.

The goal of the tomographic survey was to obtain prior information regarding the Member Catu, Marfim Formation, to develop a strategy for secondary recovery by $\mathrm{CO}_{2}$ injection.

\section{TESTS WITH SYNTHETIC DATA}

Before the inversion with real data from the Miranga Field, some tests using synthetic data were performed such that the inversion tools and the selection criteria for $\lambda$ could be evaluated. The model simulates some geological features found in the Miranga Field, especially the Catu Member from the Marfim Formation, which is an important petroleum reservoir. The acquisition parameters simulate, those used in the field to the greatest extent possible, thus showing the relative complexity in the inversion of real data.

Two wells restrict an area of $280 \times 532 \mathrm{~m}$. This area is represented as a grid formed by homogenous velocity cells. Each cell is

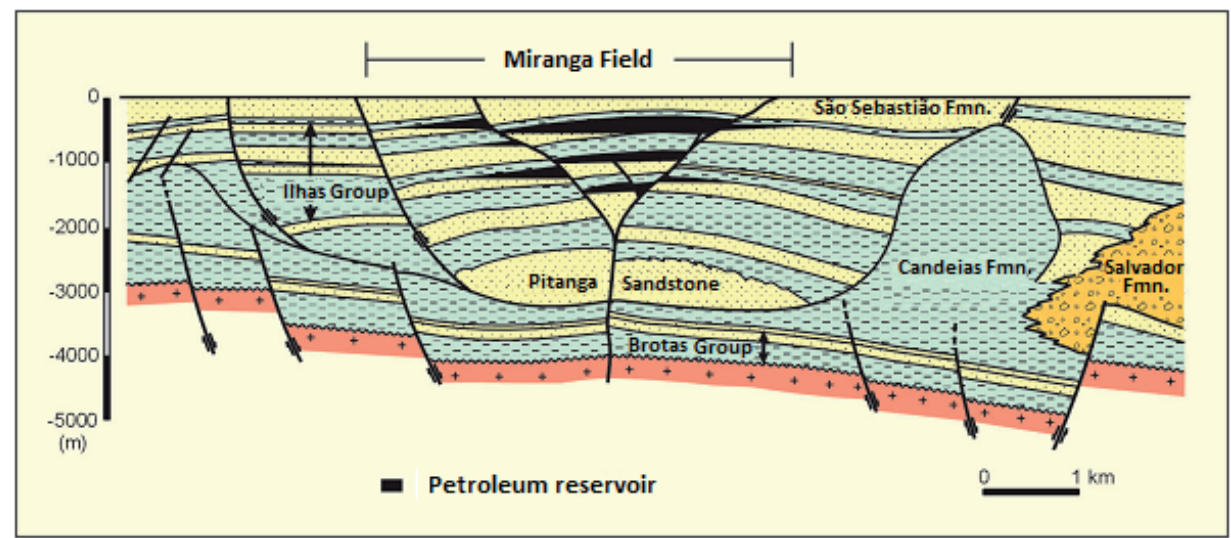

Figure 3 - Geological section from the central portion of the Recôncavo Basin showing the structural-stratigraphical situation of the Miranga Field. From Milani \& Araújo (2003). 
7 by $7 \mathrm{~m}$. In total, 134 sources and 134 receivers were simulated, each with $4 \mathrm{~m}$ of spacing, thus providing 17,956 rays. Figure 4 shows the traveltime for every source-receiver pair.

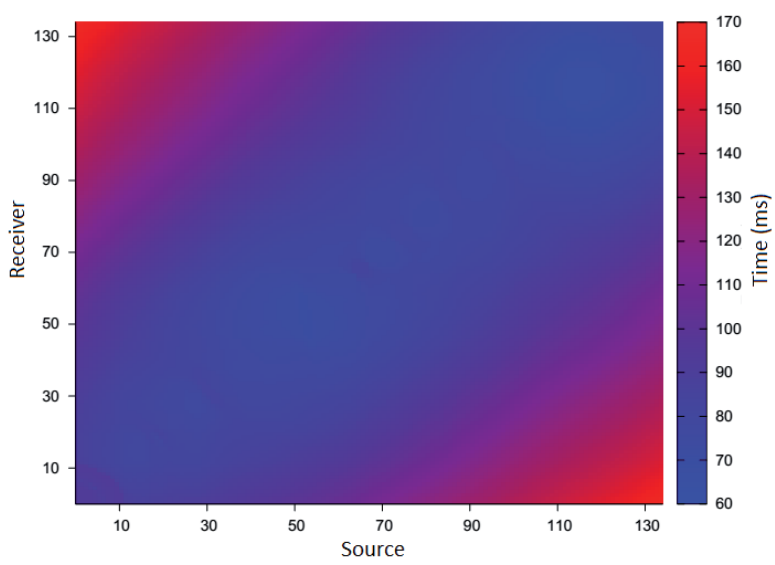

Figure 4 - Map of traveltimes between the source and the receivers of the synthetic model based on the Miranga Field.

Figure 5 shows the results for first-order regularization with synthetic data. In three iterations, even with noise added to the data, it was possible to reach some reasonable results.

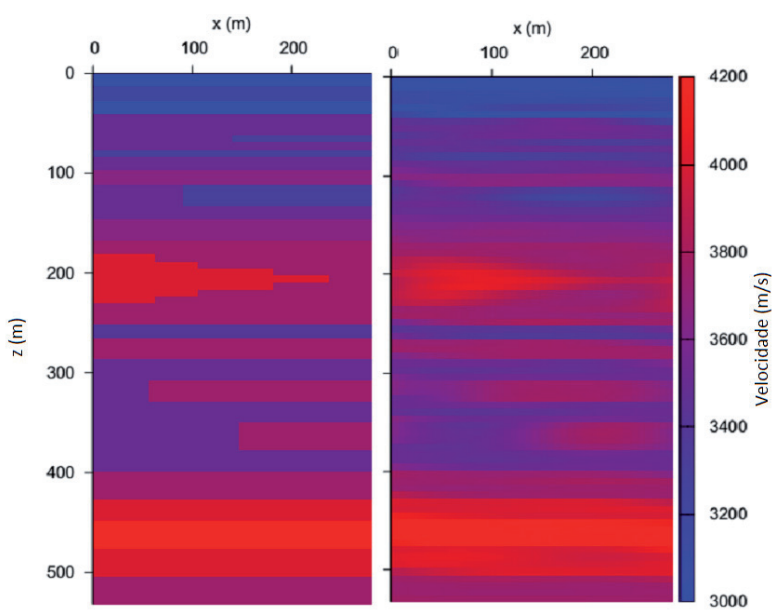

Figure 5 - Tests with the synthetic model based on the Miranga Field using first-order regularization. Left: true velocities. Right: estimated tomogram using noisy data. The color bar indicates the P-wave velocity in $\mathrm{m} / \mathrm{s}$.

The $\Theta$-curve indications (Fig. 6) were always close to the minimum of the slowness error, which reinforces the power of the method to indicate the optimal $\lambda$. However, in some cases, these indications led to nonsensical results and had to be discarded. Figures 7 and 8 present the non-correlation between the traveltime error minimum and the slowness error minimum. This difference is explained by the fact that the goal with regularization is to minimize the slowness error, not the traveltime error.

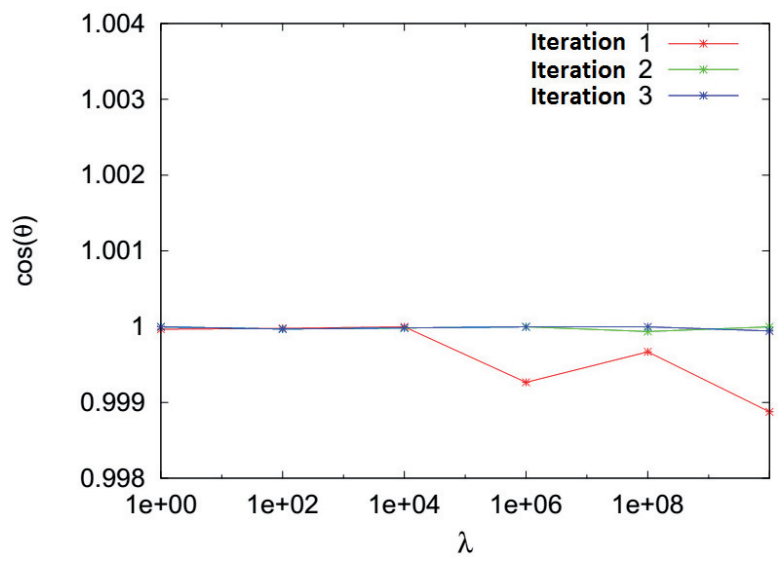

Figure 6 - Tests with the synthetic model based on the Miranga Field using first-order regularization. $\Theta$-curve from noisy data.

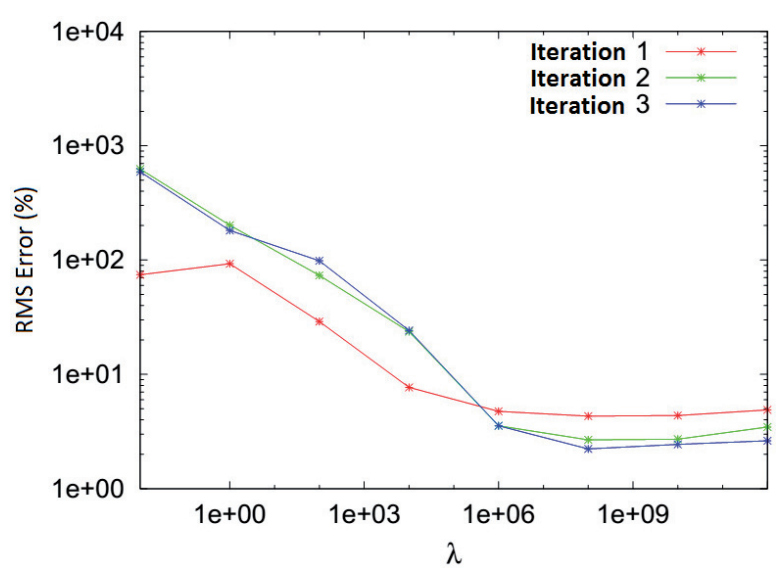

Figure 7 - Tests with the synthetic model based on the Miranga Field using firstorder regularization. RMS error between the true and the estimated slownesses for different regularization parameters.

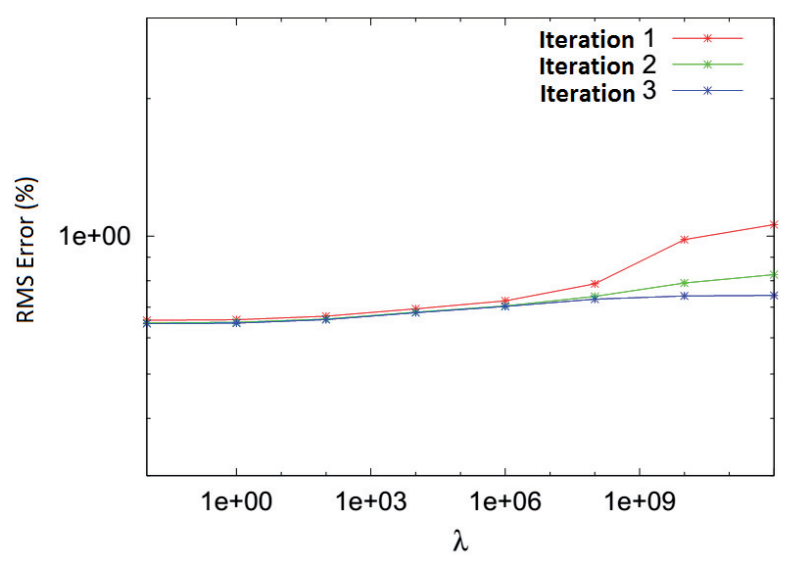

Figure 8 - Tests with the synthetic model based on the Miranga Field using first-order regularization. RMS error between the observed and the calculated traveltimes for different regularization parameters. 


\section{INVERSION WITH REAL DATA FROM THE MIRANGA FIELD}

This seismic tomography acquisition is part of a joint venture between UFBA and PETROBRAS and was performed by Schlumberger in the Miranga Field, Recôncavo Basin. The source and receivers have a measured depth interval of $3 \mathrm{~m}$ and are configured in a XWP acquisition geometry.

The source well, red color in Figure 9, shows a significant deviation from vertical, so the source coordinates must be projected into a vertical line. Schlumberger pre-processing included band pass filtering, tubewave removal and traveltime picking. In total, 16,512 traveltimes were qualified to be used in inversion.

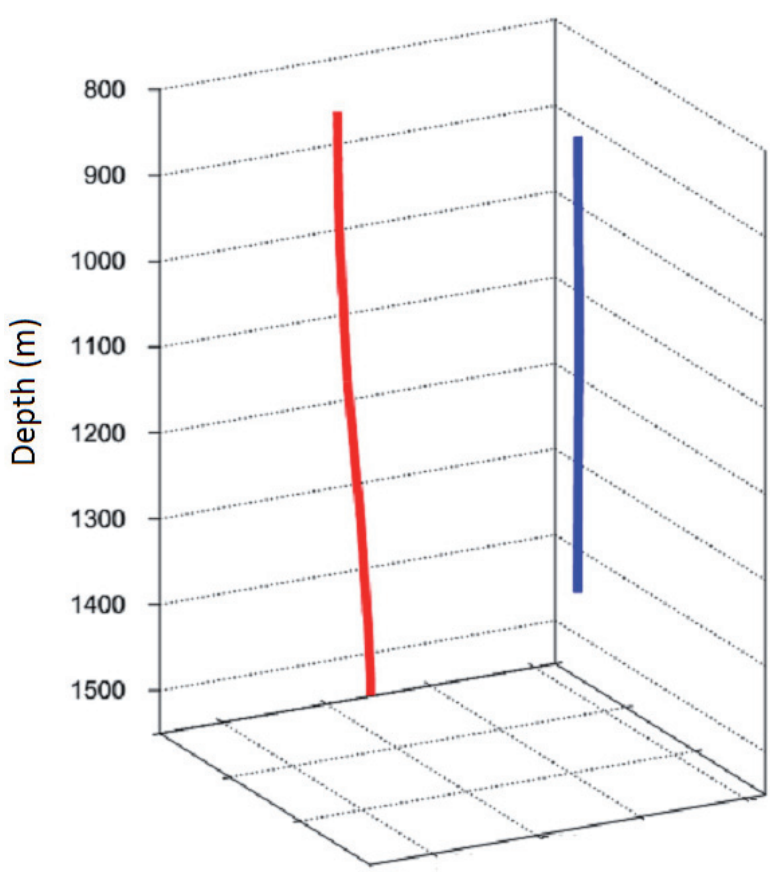

Figure $\mathbf{9}-3-D$ representation of the wells. The well with sources is in red, and the well with receivers is in blue.

Figure 10 shows the traveltime map. Clearly, considerable areas are not covered by a ray, due to the acquisition routine, equipment failure and picking error.

The region of interest is composed of a grid with 3,780 constant velocity cells that are $6 \times 6 \mathrm{~m}$ in dimension, with 42 horizontal cells and 90 vertical cells. The inversion started with a homogenous field with a velocity of $3,600 \mathrm{~m} / \mathrm{s}$.

The L-curve, $\Theta$-curve and geologic plausibility formed the set of tools for defining the regularization parameters. However, in some cases, $L$ and $\Theta$ indications led to impossible geological settings; in this case, parameters close to these indications could be an effective choice.

Figures 11 and 12 show the $\Theta$-curve for the first- and secondorder regularizations, respectively. In both Figures, the tipping point related to $\Theta$-curve minimum changes for different iterations, with the major first-order values being $\lambda=10^{6}$ and the secondorder values pointing to $\lambda=10^{10}$. However, at the correspondent $\mathrm{L}$-curve, these parameter values are not associated with the curve "knee", as would be expected, but with a second inflection point. These divergent results from the theory could be caused by the strong noisy conditions in data.

It was possible to achieve convergence in six iterations for first-order regularization and seven iterations for second-order regularization. The first and sixth iterations of the first-order are presented in Figure 13. Note that the resolution improves in advanced iterations, with refined geological features and better layer identification.

The same pattern of improved resolution with iterations can be observed in second-order regularization (Fig. 14). Second-order regularization appears to deliver a product with better resolution and more geological details, although such a qualitative comparison lacks objective parameters. In both regularizations, traveltime error had the same behavior.

Note that the optimal $\lambda$ does not match the minimum in traveltime error (Figs. 15 and 16). This finding differs from the results predicted in theory, because $\lambda$ optimally represents a balance between the minimum error and the regularization smoothness.

Table 1 - Inversion results using the real data from the Miranga Field, Recôncavo Basin. $\lambda_{\Theta}$ is the regularization parameter value indicated by the $\Theta$-curve, $\lambda$ is the chosen regularization parameter and $E_{t, r m s}$ is the relative RMS error between the observed and the calculated traveltimes.

\begin{tabular}{|c|c|c|c|c|}
\hline Order & Iteration & $\lambda_{\Theta}$ & $\lambda$ & $E_{t, r m s}(\%)$ \\
\hline \multirow{4}{*}{1} & 1 & $10^{5}$ & $10^{7}$ & 4.6675 \\
& 2 & $10^{5}$ & $10^{7}$ & 1.2345 \\
& 3 & $10^{5}$ & $10^{7}$ & 1.0692 \\
& 4 & $10^{6}$ & $10^{7}$ & 0.5985 \\
& 5 & $10^{6}$ & $10^{7}$ & 0.4595 \\
& 6 & $10^{6}$ & $10^{7}$ & 0.4390 \\
\hline & 1 & $10^{9}$ & $10^{11}$ & 4.6138 \\
& 2 & $10^{8}$ & $10^{10}$ & 1.2469 \\
& 3 & $10^{9}$ & $10^{10}$ & 0.8193 \\
& 4 & $10^{9}$ & $10^{9}$ & 0.7001 \\
& 5 & $10^{9}$ & $10^{9}$ & 0.5901 \\
& 6 & $10^{9}$ & $10^{9}$ & 0.5144 \\
& 7 & $10^{9}$ & $10^{9}$ & 0.4687 \\
\hline
\end{tabular}

\section{CONCLUSIONS}

Traveltime seismic tomography is a powerful tool for highresolution imaging. Nevertheless, two issues must be overcome: the nonlinearity of the problem and the non-uniqueness of its solution. Levenberg-Marquardt linearizes the problem at certain limits, and regularization constrains the solution space so the results become geologically realistic. 


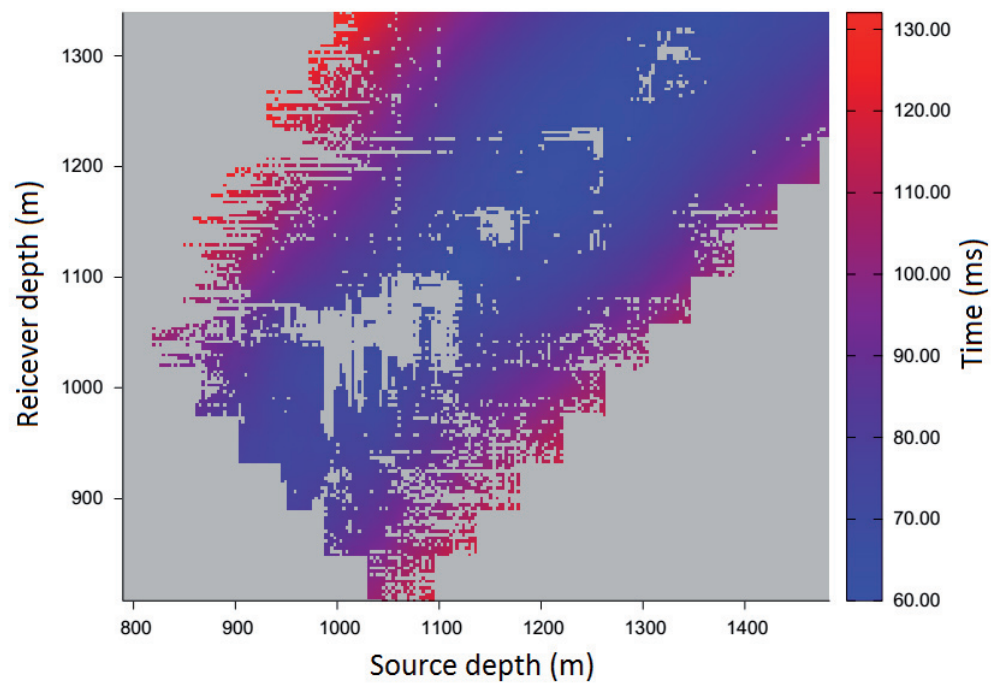

Figure 10 - Map of the traveltimes between the source and receivers of the real data from the Miranga Field.

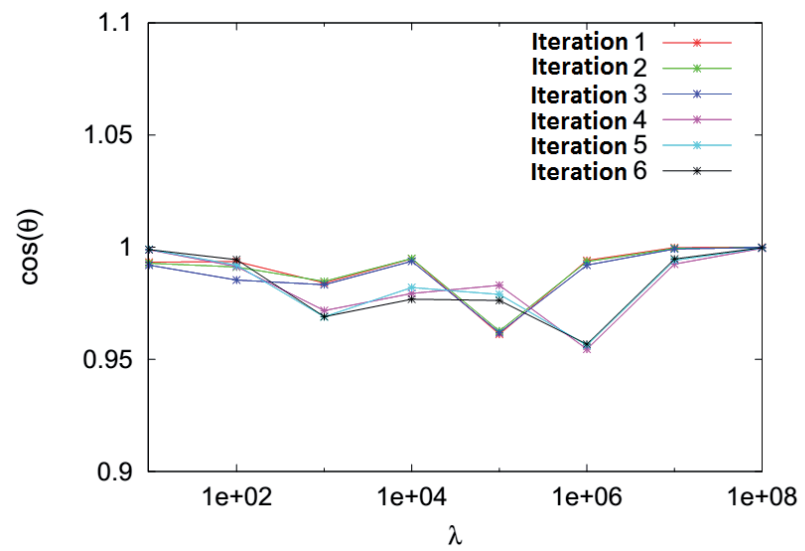

Figure 11 - Inversion with the real data from Miranga Field using first-order regularization. $\Theta$-curve for different regularization parameters.

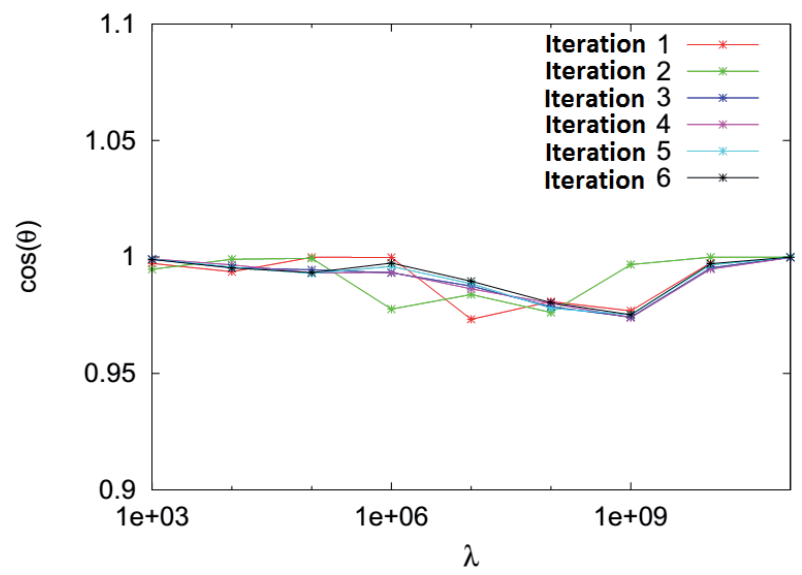

Figure 12 - Inversion with the real data from the Miranga Field using second-order regularization. $\Theta$-curve for different regularization parameters. 


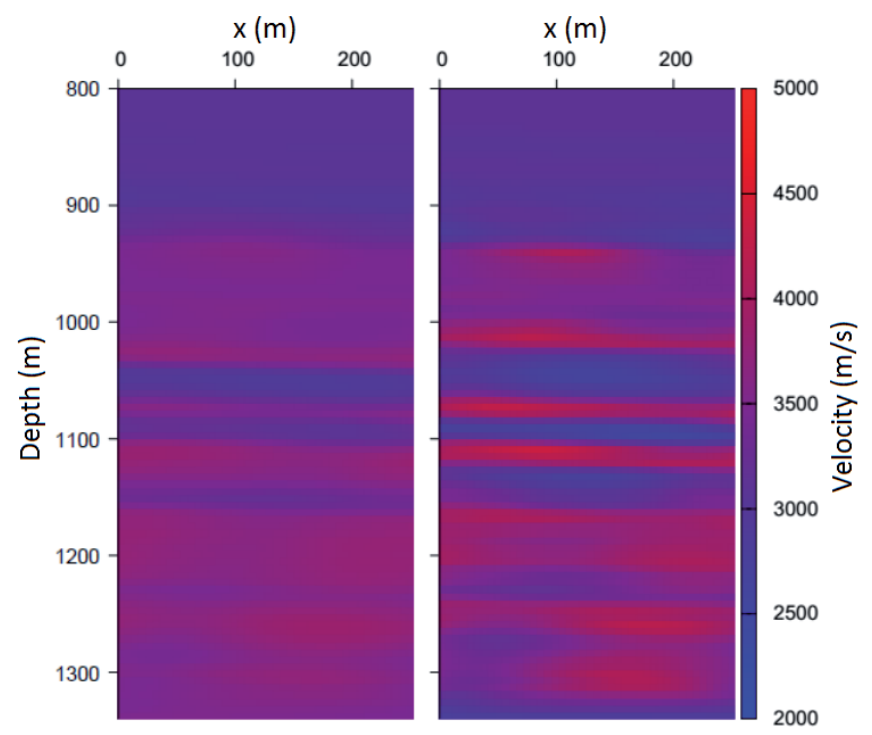

Figure 13 - Inversion with the real data from the Miranga Field using first-order regularization. Estimated tomograms from the first (left) and the sixth (right) iterations.

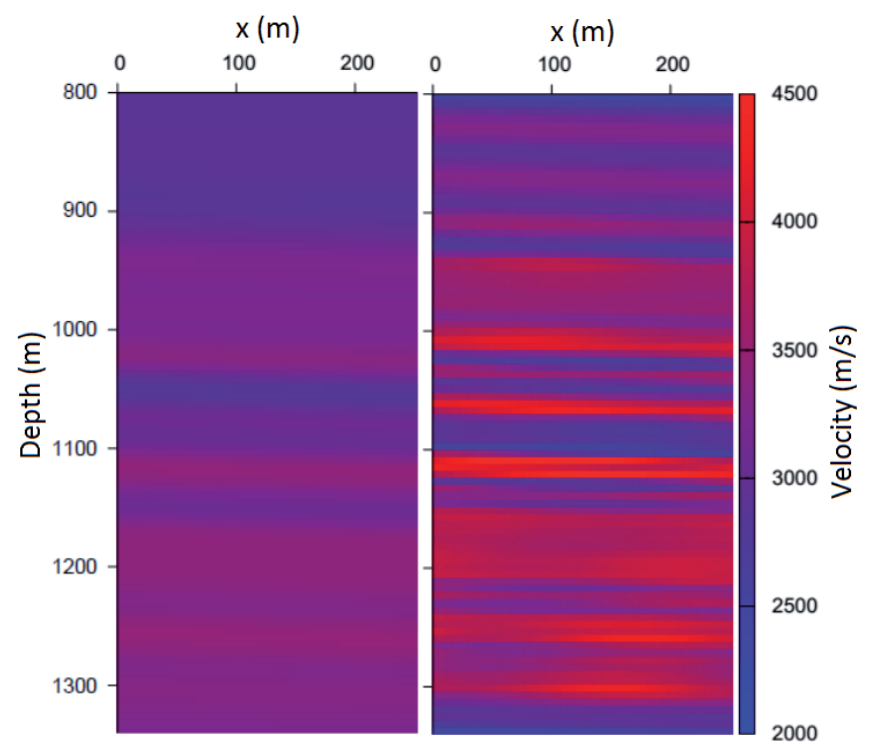

Figure 14 - Inversion with the real data from the Miranga Field using second-order regularization. Estimated tomograms from the first (left) and the seventh (right) iterations.

Some difference was perceived between the expected behavior of the L-curve and the $\Theta$-curve from theory and the results obtained in numerical simulations. The optimum regularization parameter should be associated with the L-curve "knee"; however, in some cases these values led to unrealistic geological configurations. The selected $\lambda$ values were close to the second tipping point of L-curve. This divergence is credited to strong noisy conditions.
The final result from both regularization orders appears to match the geological setting of the Miranga Field, although lacking a priori information makes this analysis difficult. Secondorder regularization was remarkable regarding the strata resolution.

As mentioned earlier, there is a significant lack of ray coverage in the region of interest, which adds uncertainty to the inversion results. In addition, no other source of geologic information 


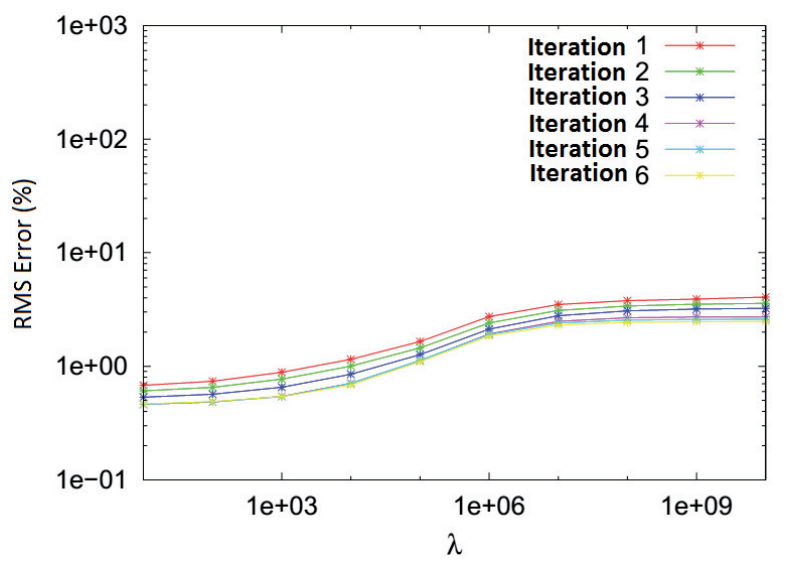

Figure 15 - Inversion with the real data from Miranga Field using first-order regularization. RMS error between the observed and the calculated traveltimes for different regularization parameters.

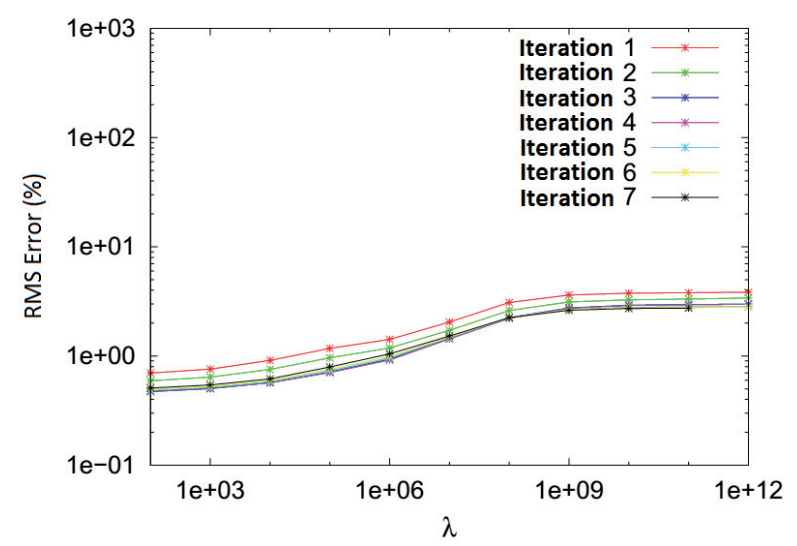

Figure 16 - Inversion with the real data from the Miranga Field using secondorder regularization. RMS error between the observed and the calculated traveltimes for different regularization parameters.

or geophysical data was used in the workflow. Such information could help restrict the model space and reduces the ambiguity related to non-uniqueness. Moreover, the well log is a valuable data that could answer some questions about the inversion reliability.

\section{ACKNOWLEDGEMENTS}

This research is part of the project "Investigation on the Use of Crosswell Tomography as a Tool for Complex Reservoir Characterization" supported by PETROBRAS. V.H.S.R. Rodrigues thanks ANP (PRH 08) for the M.Sc. scholarship. A. Bassrei thanks CNPq for the project 308.690/2013-3 (research productivity fellowship), CNPq and PETROBRAS for the support to National Institute of Science and Technology of Petroleum Geophysics (INCT-GP), and FINEP for the support to Research Network in Exploration Geophysics (Rede 01).

\section{REFERENCES}

ANDERSEN AH \& KAK AC. 1982. Digital ray tracing in two-dimensional refractive fields. Journal of Acoustical Society of America, 72(5): 15931606.

BASSREI A \& RODI W. 1993. Regularization and inversion of linear geophysical data. In: 3rd International Congress of the Brazilian Geophysical Society, vol. 1, 111-116, Brazilian Geophysical Society, Rio de Janeiro, Brazil.

EISENSTAT SC, GURSKY M, SCHULTZ MH \& SHERMAN AH. 1982. YALE sparse matrix package I: The symmetric codes. International Journal for Numerical Methods in Engineering, 18(8): 1145-1151.

HANSEN PC. 1992. Analysis of discrete ill-posed problems by means of the L-curve. Society for Industrial and Applied Mathematics Review, 34(4): 561-580. 
HESTENES MR \& STIEFEL E. 1952. Method of conjugate gradients for solving linear systems. Journal of Research of the National Bureau of Standards, 49: 409-436

JOHNSON S, GREENLEAF J, SAMAYOA W, DUCK F \& SJOSTRAND J. 1975. Reconstruction of three-dimensional velocity fields and other parameters by acoustic ray tracing. In: 1975 Ultrasonics IEEE Symposium, 46-51.

MILANI EJ \& ARAÚJO LM. 2003. Recursos minerais energéticos: petróleo. In: BIZZI LA, SCHOBBENHAUS C, VIDOTTI RM \& GONÇALVES JH (Eds.). Geologia, Tectônica e Recursos Minerais do Brasil. CPRM, Brasília, Brazil. p. 541-576.

OLIVEIRA NP. 2013. Application of Traveltime Tomography to Data from Dom João Field, Recôncavo Basin. In Portuguese with abstract in English. M.Sc. Thesis, Universidade Federal da Bahia, Salvador, Brazil, $116 \mathrm{pp}$.

SANTOS ETF. 2006. Anisotropic Seismic Tomographic Inversion with
Optimum Regularization. In Portuguese with abstract in English. Ph.D. Dissertation, Universidade Federal da Bahia, Salvador, Brazil, 148 pp.

SANTOS CF, CUPERTINO JA \& BRAGA JAE. 1990. Synthesis on the geology of Recôncavo, Tucano and Jatobá Basins. In Portuguese. In: GABAGLIA GPR \& MILANI EJ (Org.). Origin and Evolution of Sedimentary Basins. PETROBRAS, Rio de Janeiro, Brazil. p. 235-266.

SEN MK \& STOFFAPL. 2013. Global Optimization Methods in Geophysical Inversion. Cambridge University Press, Cambridge, UK, 302 pp.

SNIEDER R \& TRAMPERT J. 1999. Inverse problems in geophysics. In: WIRGIN A (Ed.). Wavefield Inversion. Springer, New York. p. 119190.

TWOMEY S. 1963. On the numerical solution of Fredholm integral equations of the first kind by the inversion of the linear system produced by quadrature. Journal of the Association of Computing Machinery, 10(1): 97-101. 